\title{
Capim-elefante ensilado com casca de café, farelo de cacau ou farelo de mandioca ${ }^{1}$
}

\author{
Aureliano José Vieira Pires ${ }^{2,8}$, Gleidson Giordano Pinto de Carvalho ${ }^{3}$, Rasmo Garcia ${ }^{4,8}$, José \\ Nobre de Carvalho Junior ${ }^{5}$, Leandro Sampaio Oliveira Ribeiro ${ }^{6}$, Daiane Maria Trindade Chagas $^{7}$
}

${ }^{1}$ Projeto financiado pelo CNPq.

2 DTRA, UESB, Itapetinga, BA. Av. das Palmeiras, 491, Bairro Morumbi, CEP: 45.700-000, Itapetinga-BA.

${ }^{3}$ Doutorando em Zootecnia, UFV, Viçosa, MG. Bolsista do CNPq.

${ }^{4}$ DZO, UFV, Viçosa, MG.

5 Zootecnista, MSc., UESB, Itapetinga, BA.

${ }^{6}$ Graduando em Zootecnia, UESB, Itapetinga, BA. Bolsista de Iniciação Científica do CNPq.

${ }^{7}$ Graduanda em Zootecnia, UESB, Itapetinga, BA. Bolsista de Iniciação Científica da FAPESB.

${ }^{8}$ Pesquisador do CNPq.

RESUMO - Este experimento foi conduzido para avaliar a composição química, a digestibilidade in vitro da matéria seca (DIVMS) e as características fermentativas de silagens de capim-elefante com $15 \%$ de casca de café, farelo de cacau ou farelo de mandioca. A adição dos co-produtos no momento da ensilagem foi realizada na base da matéria natural (peso/ peso), com dez repetições por tipo de silagem. As silagens com casca de café e farelo de mandioca apresentaram maiores teores de matéria seca. A silagem com farelo de mandioca apresentou os menores teores de nitrogênio total, extrato etéreo e componentes fibrosos. O maior valor de DIVMS foi observado na silagem com farelo de mandioca $(74,1 \%)$ e o menor, na silagem com casca de café $(54,3 \%)$. As silagens controle e com farelo de cacau apresentaram valores de digestibilidade semelhantes, 61,4 e 61,2\%, respectivamente. Na avaliação das características fermentativas das silagens, não houve diferença entre os teores de ácidos orgânicos, porém o pH da silagem com casca de café $(4,6)$ foi superior ao das demais silagens (4,1). A utilização de farelo de mandioca na ensilagem de capim-elefante reduz os componentes da parede celular e aumenta a DIVMS das silagens. Tanto a casca de café como o farelo de cacau adicionados no momento da ensilagem reduzem o valor nutritivo da silagem.

Palavras-chave: conservação, forrageiras, Pennisetum purpureum, subproduto

\section{Elephant grass ensiled with coffee hulls, cocoa meal and cassava meal}

\begin{abstract}
The experiment was carried out to evaluate the chemical composition, the in vitro dry matter digestibility (IVDMD) and the fermentative characteristics of elephant grass silage with $15 \%$ of coffee hulls, cocoa meal or cassava meal. The addition of co-products at the ensilage moment was performed in the natural matter basis (weight/ weight), with ten repetitions per treatment. Silages with coffee hulls and cassava meal showed higher dry matter levels. The silage with cassava meal presented smaller total nitrogen, ether extract and fibrous components levels. The highest IVDMD value was observed for silage with cassava meal (74.1\%) and the value lowest for silage with coffee hulls (54.3\%). The control silage and that with the addition of cocoa meal showed similar digestibility values, 61.4 and $61.2 \%$, respectively. Regarding the fermentative characteristics of silages, no difference was observed between the organic acids levels, even though silage with coffee hulls showed $\mathrm{pH}$ value (4.6) above other silages (4.1). The use of cassava meal in elephant grass ensilage reduces the cell wall components and increases the IVDMD of silages. Both coffee hulls and cocoa meal added at the ensilage moment decrease the silage nutritional value.
\end{abstract}

Key Words: by-product, conservation, forages, Pennisetum purpureum

\section{Introdução}

A produção de silagem constitui alternativa para suprir a demanda de nutrientes dos animais no período crítico do ano. Entre as forrageiras utilizadas com esta finalidade, o capim-elefante tem se destacado em diversas pesquisas realizadas no País (Bernardino et al., 2005; Carvalho et al., 2007a), principalmente por apresentar elevada produção de matéria seca (Andrade \& Lavezzo, 1998).

Apesar do potencial para produção de silagem, o baixo teor de carboidratos solúveis dessa forrageira é fator limitante e, portanto, se contrapõe aos parâmetros reco- 
mendados e referenciados para produção de silagem de boa qualidade. A ensilagem de gramíneas com baixo teor desses carboidratos favorece as perdas durante o processo de ensilagem (Bernardino et al., 2005) e, aliada ao elevado teor de umidade da forrageira, propicia o desenvolvimento de bactérias do gênero Clostridium. O desenvolvimento dessas bactérias produz fermentações secundárias indesejáveis e formação de ácido butírico, o que caracteriza silagens de baixa qualidade (McDonald, 1981), pois, quando há formação de ácido butírico, concomitantemente ocorre degradação de proteínas e de ácido lático.

Neste sentido, diversos autores têm buscado alternativas para aumentar o teor de carboidratos solúveis na massa ensilada de capim-elefante e melhorar seu valor nutritivo, como a técnica de emurchecimento do capim (Carvalho et al., 2007a) e/ou uso de aditivos, como polpa cítrica (Rodrigues et al., 2005), co-produtos da indústria do suco de caju (Ferreira et al., 2004), farelo de mandioca (Ferrari Jr. \& Lavezzo, 2001) e farelo de trigo (Zanine et al., 2006). Entretanto, o emurchecimento do capim aumenta o tempo entre o corte e a vedação do silo, resultando em maiores perdas, em decorrência do processo respiratório e da atividade proteolítica da planta, que resultam na redução de substratos fermentáveis e aumento do nitrogênio não-protéico (McDonald, 1981).

A casca de café, o farelo de cacau e o farelo de mandioca têm potencial para utilização na alimentação de ruminantes. Relatos na literatura indicam a possibilidade de utilização desses co-produtos na alimentação de bovinos, ovinos e caprinos. Contudo, resultados de pesquisas avaliando a utilização desses alimentos na ensilagem de capim-elefante ainda são incipientes.

Realizou-se este experimento para avaliar a composição química, a digestibilidade in vitro da matéria seca e as características fermentativas de silagens de capimelefante contendo casca de café, farelo de cacau ou farelo de mandioca.

\section{Material e Métodos}

Utilizou-se capim-elefante (Pennisetum purpureum, Schum. cv. Napier) proveniente de uma capineira já estabelecida, pertencente à Universidade Estadual do Sudoeste da Bahia, UESB, Itapetinga, Bahia. Quando apresentava altura média de 1,8 m, aos 80 dias de rebrota, o capim foi colhido, picado em partículas de $2 \mathrm{~cm}$ e ensilado, resultando em quatro tipos de silagem: capim-elefante (controle); capim-elefante (85\%) + casca de café (15\%); capim-elefante $(85 \%)+$ farelo de cacau $(15 \%)$ e capimelefante (85\%) + farelo de mandioca (15\%).
A adição dos co-produtos foi realizada logo após o corte e a picagem do capim, na base da matéria natural (peso/peso) (Tabela 1). Para a ensilagem, foram utilizados tambores de metal com volume de $200 \mathrm{~L}$ por tipo de silagem. Em cada silo foram colocados $90 \mathrm{~kg}$ da mistura fresca, em densidade de $450 \mathrm{~kg} / \mathrm{m}^{3}$.

Após 60 dias de armazenamento, os silos foram abertos para coleta de amostras, que foram congeladas para posteriores análises. Parte das amostras foi descongelada em temperatura ambiente, acondicionada em sacos de papel e mantida em estufa para pré-secagem, por 72 horas a $60^{\circ} \mathrm{C}$. Em seguida, foi triturada em moinho tipo Wiley com peneira com malha de $1 \mathrm{~mm}$.

As amostras foram transportadas para o Departamento de Zootecnia da Universidade Federal de Viçosa para as análises químicas, realizadas nos Laboratórios de Forragicultura e Nutrição Animal. Foram determinados os teores de nitrogênio total (NT), fibra em detergente neutro (FDN), fibra em detergente neutro isenta de cinza e proteína (FDNcp), fibra em detergente ácido (FDA), extrato etéreo (EE), celulose, hemicelulose, lignina, nitrogênio insolúvel em detergente neutro (NIDN) e nitrogênio insolúvel em detergente ácido (NIDA) e a digestibilidade in vitro da matéria seca (DIVMS), segundo metodologias descritas por Silva \& Queiroz (2002).

Os carboidratos solúveis foram extraídos por fervura em água e estimados por colorimetria, segundo procedimentos descritos por Silva \& Queiroz (2002).

Parte da silagem in natura (50 g) foi triturada com 200 mL de água, em liquidificador industrial, e filtrada

Tabela 1 - Composição química dos alimentos antes da ensilagem (\% MS)

\begin{tabular}{lrrrr}
\hline Item & $\begin{array}{c}\text { Capim- } \\
\text { elefante }\end{array}$ & $\begin{array}{c}\text { Casca de } \\
\text { café }\end{array}$ & $\begin{array}{c}\text { Farelo de } \\
\text { cacau }\end{array}$ & $\begin{array}{c}\text { Farelo de } \\
\text { mandioca }\end{array}$ \\
\hline Matéria seca & 28,3 & 89,8 & 86,0 & 88,8 \\
Matéria orgânica & 94,0 & 94,4 & 91,2 & 98,5 \\
Matéria mineral & 6,0 & 5,6 & 8,8 & 1,5 \\
Nitrógeno total & 0,9 & 1,2 & 2,4 & 0,4 \\
Extrato etéreo & 2,3 & 0,8 & 2,6 & 0,8 \\
FDNcp & 72,7 & 73,5 & 45,7 & 11,3 \\
Fibra em & 43,0 & 57,7 & 33,8 & 6,6 \\
detergente ácido & & & & \\
Hemicelulose & 29,8 & 15,8 & 11,9 & 4,7 \\
Celulose & 36,3 & 41,6 & 17,8 & 4,5 \\
Lignina & 5,4 & 16,1 & 15,6 & 1,0 \\
Carboidratos totais & 85,8 & 86,4 & 73,6 & 95,2 \\
Carboidratos & 17,1 & 18,3 & 39,6 & 92,4 \\
não-fibrosos & & & & \\
NIDN/NT & 22,2 & 52,3 & 44,2 & 12,5 \\
NIDA/NT & 6,0 & 38,6 & 39,7 & 10,2 \\
\hline
\end{tabular}

FDNcp - fibra em detergente neutro corrigida para cinzas e proteína; NIDN nitrogênio insolúvel em detergente neutro (porcentagem do nitrogênio total); NIDA - nitrogênio insolúvel em detergente ácido (porcentagem do nitrogênio total). 
em gaze para extração do meio aquoso, utilizado imediatamente para análise do nitrogênio amoniacal $\left(\mathrm{N}-\mathrm{NH}_{3}\right)$ e do $\mathrm{pH}$. O teor de $\mathrm{N}-\mathrm{NH}_{3}$ foi estimado imediatamente, em porcentagem do N-total, utilizando-se óxido de magnésio e cloreto de cálcio, segundo Cunniff (1995).

Os teores dos ácidos lático, acético e butírico foram quantificados em cromatógrafo a gás, conforme metodologia descrita por Boin (1975).

O delineamento experimental adotado foi o inteiramente casualizado, com quatro tratamentos e dez repetições. Realizaram-se análise variância e comparação das médias pelo teste Tukey a 5\% de probabilidade, utilizando-se o programa Sistema de Análises Estatísticas e Genéticas SAEG (Ribeiro Jr., 2001).

\section{Resultados e Discussão}

O teor de matéria seca foi semelhante (Tabela 2) entre as silagens com casca de café e farelo de mandioca, enquanto os valores determinados nas silagens controle $(33,7 \%)$ e com farelo de cacau $(41,6 \%)$ foram menores. Os maiores valores de matéria seca observados nas silagens com casca de café e farelo de mandioca podem ser explicados pelo elevado teor de matéria seca desses aditivos (Tabela 1). Apesar de os baixos teores de matéria seca terem sido menores nas silagens controle e com farelo de cacau, os valores observados para todas as silagens foram superiores ao de 25\% recomendados por Andrade (1995) como mínimo para que não ocorram perdas por efluente na ensilagem de capim-elefante. Souza et al. (2003), em pesquisa com ensilagem de capim-elefante (14,5\% de MS), verificaram 34,3\% de MS em silagem contendo 34,8\% de casca de café. O maior valor de matéria seca obtido neste estudo pode ser atribuído ao maior teor de matéria seca do capim antes da ensilagem (28,3\%).
O teor de nitrogênio total diferiu entre as silagens, mas foi maior $(\mathrm{P}<0,05)$ naquelas contendo farelo de cacau, o que está relacionado ao maior teor de proteína desse co-produtos. O farelo de mandioca, no entanto, por apresentar baixo teor de nitrogênio total, ao ser incluído na silagem de capimelefante, gerou silagens com teores de nitrogênio total inferiores aos das demais silagens. É comum a perda de compostos nitrogenados solúveis no efluente quando a umidade no interior na massa ensilada é elevada (Souza et al., 2003), contudo, no momento de abertura dos silos, não se observou presença de efluente, o que pode ter favorecido a preservação do teor de nitrogênio total nas silagens.

A silagem de capim-elefante com farelo de cacau apresentou maior $(\mathrm{P}<0,05)$ teor de extrato etéreo $(4,1 \%)$ possivelmente em virtude do maior teor deste componente no farelo de cacau (2,6\%) em comparação aos demais aditivos utilizados. Os valores de extrato etéreo nas silagens estão de acordo com relatos na literatura (Carvalho et al., 2007a,b) em níveis que não prejudicariam o desempenho animal. De acordo com Staples et al. (2001), elevados teores de lipídeos na dieta de ruminantes promovem o envolvimento físico da fibra da fibra e impedem o ataque microbiano, reduzindo a digestibilidade in vitro da matéria seca.

Houve efeito dos aditivos $(\mathrm{P}<0,05)$ sobre o teor de fibra em detergente neutro das silagens. A silagem controle e aquela com casca de café (Tabela 2) foram superiores às demais silagens. Os menores valores de FDNcp foram obtidos nas silagens com farelo de cacau (63,6\%) e farelo de mandioca (58,0\%), o que pode ser explicado pelo baixo teor de FDNcp desses aditivos, 45,7 e 11,3\%, respectivamente. O teor de FDNcp de 72,6\% obtido na silagem com casca de café foi superior ao encontrado por Souza et al. (2003) ao utilizarem casca de café na ensilagem de capimelefante com 14,45\% de MS. O maior valor encontrado neste trabalho pode ser atribuído ao maior teor de fibra do

Tabela 2 - Composição química de silagens de capim-elefante contendo diferentes co-produtos

\begin{tabular}{|c|c|c|c|c|c|c|}
\hline \multirow[t]{2}{*}{ Item } & \multicolumn{4}{|c|}{ Silagem de capim-elefante } & \multirow[t]{2}{*}{$\mathrm{CV}$} & \multirow[t]{2}{*}{ Valor-P } \\
\hline & Controle & Com casca de café & Com farelo de cacau & Com farelo de mandioca & & \\
\hline Matéria seca & $33,7 c$ & $43,6 a$ & $41,6 b$ & $43,6 a$ & 2,7 & $<0,0001$ \\
\hline Nitrogênio total ${ }^{1}$ & $0,8 \mathrm{c}$ & $1,0 \mathrm{~b}$ & $1,2 \mathrm{a}$ & $0,6 \mathrm{~d}$ & 5,2 & $<0,0001$ \\
\hline Extrato etéreo ${ }^{1}$ & $2,9 b$ & $2,8 \mathrm{bc}$ & $4,1 \mathrm{a}$ & $2,2 c$ & 17,9 & $<0,0001$ \\
\hline FDNcp $^{1}$ & $71,3 \mathrm{a}$ & $72,6 a$ & $63,6 b$ & $58,0 \mathrm{c}$ & 3,1 & $<0,0001$ \\
\hline Fibra em detergente ácido ${ }^{1}$ & $42,2 b$ & $48,6 a$ & $42,4 b$ & $31,7 c$ & 4,0 & $<0,0001$ \\
\hline Celulose $^{1}$ & $38,3 a$ & $39,4 \mathrm{a}$ & $32,6 b$ & $27,7 \mathrm{C}$ & 7,2 & $<0,0001$ \\
\hline Hemicelulose ${ }^{1}$ & $32,5 a$ & $28,1 b$ & $25,7 c$ & $29,5 b$ & 6,4 & $<0,0001$ \\
\hline Lignina $^{1}$ & $5,2 b$ & $9,8 \mathrm{a}$ & $9,8 \mathrm{a}$ & $4,1 \mathrm{c}$ & 7,9 & $<0,0001$ \\
\hline $\mathrm{NIDN}^{2}$ & $20,1 \mathrm{c}$ & $32,1 b$ & $42,1 \mathrm{a}$ & $28,5 b$ & 12,3 & $<0,0001$ \\
\hline NIDA $^{2}$ & $8,5 b$ & $20,6 a$ & $20,9 a$ & $9,5 b$ & 12,6 & $<0,0001$ \\
\hline
\end{tabular}

CV - coeficiente de variação (\%); 1 \% da matéria seca; ${ }^{2} \%$ do nitrogênio total.

FDNcp - fibra em detergente neutro isenta de cinzas e proteína; NIDN - nitrogênio insolúvel em detergente neutro; NIDA - nitrogênio insolúvel em detergente ácido. 
capim-elefante utilizado. Redução na concentração de fibra em detergente neutro de dietas contendo alta proporção de volumosos pode contribuir para aumentar o consumo de matéria seca e, ao mesmo tempo, aumentar a densidade energética de rações para ruminantes (Van Soest, 1994; Souza et al., 2003). Rezende et al. (2002) verificaram que as porcentagens de FDNcp reduziram linearmente com a mistura de 0 , 25, 50, 75 ou $100 \%$ de girassol na ensilagem de capim-elefante. Redução nos teores de FDNcp e FDA foi observada também por Zanine et al. (2006) ao utilizarem farelo de trigo na ensilagem de capim-elefante.

A silagem com casca de café apresentou os maiores teores de FDA (48,6\%). Entre os alimentos utilizados neste experimento, a casca de café foi o que apresentou maior teor de FDA, que foi superior, inclusive, ao do capim-elefante, o que explica os maiores valores de FDA nas silagens produzidas com esse co-produtos. Bernadino et al. (2005) não observaram influência nos valores de FDA e celulose com adição de casca de café em diferentes níveis ao capimelefante com 12,4\% de MS no momento da ensilagem. Os teores de celulose diferiram entre as silagens com adição de farelo de cacau (32,6\%) e farelo de mandioca $(27,7 \%)$, que apresentaram os menores valores. As silagens sem aditvo e com adição de casca de café, todavia, apresentaram valores semelhantes de celulose.

Os valores de hemicelulose obtidos para as silagens com casca de café ou farelo de mandioca apresentaram valores intermediários e semelhantes entre si. Os valores encontrados foram próximos aos obtidos por Carvalho et al. (2007a) ao estudarem a adição de farelo de cacau na ensilagem de capim-elefante. Ferrari Jr. \& Lavezzo (2001), no entanto, verificaram redução linear nos teores de hemicelulose ao adicionarem farelo de mandioca na ensilagem de capim-elefante.

Os teores de lignina das silagens com casca de café e farelo de cacau foram semelhantes entre si e superiores aos observados nas silagens controle e com farelo de mandioca $(\mathrm{P}<0,05)$. Os maiores teores de lignina na casca de café e no farelo de cacau e o baixo teor no farelo de mandioca explicam os resultados observados.

Não houve diferença $(\mathrm{P}>0,05)$ entre a silagem com casca de café ou farelo de mandioca para o teor de NIDN (\%NT), que foi maior $(42,1 \%)$ na silagem com farelo de cacau. Os teores de NIDA (\%NT) das silagens com casca de café ou farelo de cacau também foram maiores (20,6 e 20,9\%, respectivamente) que os obtidos nas demais silagens. Esses resultados podem ser explicados pelos maiores valores de NIDA no farelo de cacau e na casca de café utilizados nas silagens (Tabela 1). Elevado teor de NIDA não é desejável, pois o nitrogênio retido na fibra em detergente ácido não é aproveitado pelos microrganismos ruminais (Van Soest \& Mason, 1991). Rodrigues et al. (2005) verificaram redução no teor de NIDA até o nível de 4,7\% de polpa cítrica. Em quantidades superiores, os valores elevaram, sugerindo que o acréscimo de polpa cítrica nas silagens promove aumento de frações indigeríveis do nitrogênio. Aumento nos teores de NIDA também foi observado por Souza et al. (2003), Bernadino et al. (2005) e Carvalho et al. (2007b) utilizando a casca de café na ensilagem de capim-elefante.

Os valores de DIVMS das silagens (Figura 1) controle e com farelo de cacau foram semelhantes. O maior valor $(\mathrm{P}<0,05)$ de DIVMS foi observado na silagem com farelo de mandioca (74,1\%). Tudo indica que o baixo teor de lignina no farelo de mandioca utilizado na ensilagem contribuiu para a maior digestibilidade da silagem produzida. Por outro lado, os maiores valores de lignina na casca de café e no farelo de cacau podem ter acarretado menores digestibilidades nas silagens. Carvalho et al. (2007a) verificaram redução na DIVMS de silagens acrescidas de farelo de cacau (0, 7, 14, 21 e 28\%). Do mesmo modo, Souza et al. (2003) observaram redução na DIVMS de silagens acrescidas de casca de café. Os autores verificaram decréscimo de 0,14 unidades percentuais no valor da DIVMS por unidade de casca de café adicionada. Os valores médios estimados pela equação foram de 64,48 ; 63,$24 ; 62,00 ; 60,77$ e 59,53\% para 0; 8,7; 17,4; 26,1 e 34,8\% de casca de café, respectivamente.

A silagem com casca de café apresentou o maior valor de $\mathrm{pH}(4,6)$, que, na silagem sem aditivo, foi de 4,2 e não diferiu entre as silagens com adição de farelo de cacau $(4,2)$ ou farelo de mandioca $(4,1)$ (Tabela 3). Com exceção da

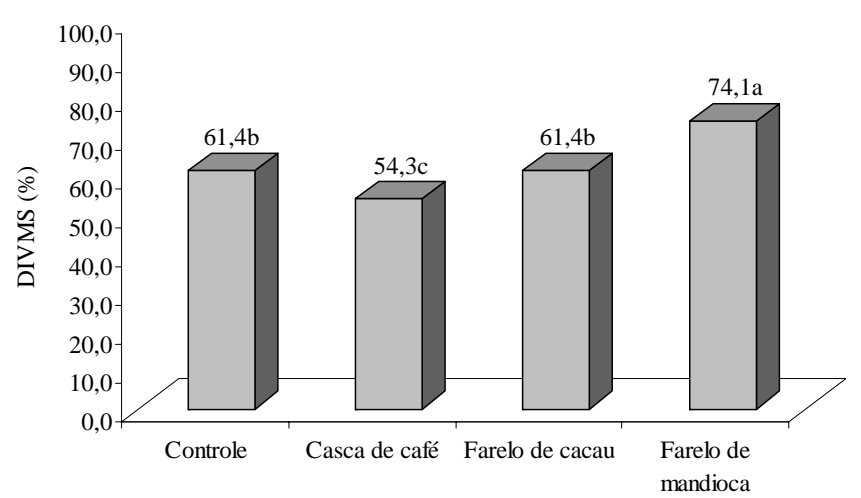

Figura 1 - Digestibilidade in vitro da matéria seca (DIVMS) de silagens de capim-elefante contendo diferentes co-produtos. Médias seguidas de mesma letra não diferem $(\mathrm{P}<0,0001)$ entre si pelo teste Tukey a $5 \%$. 
Tabela 3 - Valores de pH e teores médios de carboidratos solúveis, nitrogênio amoniacal $\left(\mathrm{N}_{-} \mathrm{NH}_{3}\right)$ e ácidos lático, acético e butírico das silagens de capim-elefante contendo diferentes co-produtos

\begin{tabular}{|c|c|c|c|c|c|c|}
\hline Item & \multicolumn{4}{|c|}{ Silagem de capim-elefante } & $\mathrm{CV}$ & Valor-P \\
\hline $\mathrm{pH}$ & $4,2 b$ & $4,6 a$ & $4,2 b$ & $4,1 b$ & 2,0 & $<0,0001$ \\
\hline $\mathrm{N}-\mathrm{NH}_{3}$ (\% do nitrogênio total) & $2,1 b$ & $1,3 \mathrm{c}$ & $2,3 b$ & $4,6 a$ & 7,0 & $<0,0001$ \\
\hline Ácido lático (\% da MS) & 4,6 & 3,8 & 5,2 & 4,7 & 24,0 & 0,1902 \\
\hline Ácido acético (\% da MS) & 0,67 & 0,70 & 0,54 & 0,61 & 27,8 & 0,2682 \\
\hline
\end{tabular}

$\mathrm{CV}=$ coeficiente de variação (\%).

Médias seguidas de mesma letra na linha não diferem estatisticamente a 5\% pelo teste Tukey.

silagem com casca de café, as demais silagens apresentaram valores de $\mathrm{pH}$ dentro da faixa considerada ideal para fermentação adequada, que, segundo McDonald (1981) é de 3,8 a 4,2. O pH elevado, em silagens convencionalmente conservadas, é indicativo de maior produção de ácido acético e butírico, que são característicos dos processos de fermentações indesejáveis (Van Soest, 1994). Embora a silagem com casca de café tenha apresentado valor de $\mathrm{pH}$ acima de 4,2, não se verificou produção excessiva de ácido acético ou butírico. Os açúcares residuais representados pelos carboidratos solúveis variaram entre as silagens, contudo os valores de ácido lático, acético e butírico foram semelhantes. Os valores de ácido butírico e $\mathrm{N}-\mathrm{NH}_{3}$ foram baixos em todas as silagens, o que indica ausência de fermentações indesejáveis resultantes da ação das bactérias do gênero Clostridium, uma vez que estas conduzem ao desdobramento de açúcares, ácido lático e aminoácidos, com produção de ácido butírico e acético, $\mathrm{N}-\mathrm{NH}_{3}$, aminas, amônia e gases, prejudicando o valor nutritivo da silagem (McDonald, 1981).

Os valores de ácido lático obtidos para as silagens foram superiores a 3,0\%, o que caracteriza uma silagem de boa qualidade (Vilela, 1990; Ferrari Jr. \& Lavezzo, 2001). O ácido lático possui poder de acidificação mais acentuada em comparação aos outros ácidos produzidos e, portanto, é o principal ácido responsável pela rápida queda e pela manutenção do pH. Todos os valores de ácido acético verificados nas silagens foram inferiores a $0,8 \%$. Segundo Rodrigues et al. (2005), níveis de ácido acético superiores a $0,8 \%$ indicam alterações indesejáveis durante o processo de ensilagem.

\section{Conclusões}

A utilização de casca de café, farelo de cacau ou farelo de mandioca na ensilagem de capim-elefante resulta em silagens com características fermentativas adequadas, contudo, tanto a casca de café como o farelo de cacau reduzem o valor nutritivo da silagem.

O uso de farelo de mandioca na ensilagem de capimelefante reduz os componentes da parede celular e aumenta a digestibilidade in vitro da matéria seca das silagens.

\section{Literatura Citada}

ANDRADE, J.B. Efeito da adição de rolão de milho, farelo de trigo e sacharina na silagem de capim-elefante (Pennisetum purpureum, Schum.). 1995. 190f. Tese (Doutorado em Zootecnia) - Faculdade de Medicina Veterinária e Zootecnia, Universidade Estadual Paulista, Botucatu, 1995.

ANDRADE, J.B.; LAVEZZO, W. Aditivos na ensilagem de capimelefante. I. Composição bromatológica das forragens e das respectivas silagens. Pesquisa Agropecuária Brasileira, v.33, n.11, p.1859-1872, 1998.

BERNARDINO, F.S.; GARCIA, R.; ROCHA, F.C. et al. Produção e características do efluente e composição bromatológica da silagem de capim-elefante contendo diferentes níveis de casca de café. Revista Brasileira de Zootecnia, v.34, n.6, p.21852291, 2005.

BOIN, C. Elephant (Napier) grass silage production, effect of addotion on chemical composition, nutritive value and animal performances. 1975. 215f. Thesis (Doctor in Animal Nutrition) - Cornell University, Ithaca, 1975.

CARVALHO, G.G.P.; GARCIA, R.; PIRES, A.J.V. et al. Valor nutritivo de silagens de capim-elefante emurchecido ou com adição de farelo de cacau. Revista Brasileira de Zootecnia, v.36, n.5, p.1495-1501, 2007a.

CARVAlHO, G.G.P.; GARCIA, R.; PIRES, A.J.V. et al. Valor nutritivo e características fermentativas de silagem de capimelefante com adição de casca de café. Revista Brasileira de Zootecnia, v.36, n.6, p.1875-1881, 2007b.

CUNNIFF, P. Official methods of analysis of AOAC International. 16.ed. Arlington: AOAC International, 1995. v.1. p.1-37.

FERRARI JR., E.; LAVEZZO, W. Qualidade da silagem de capimelefante (Pennisetum purpurum Shum) emurchecimento ou acrescido de farelo de mandioca. Revista Brasileira de Zootecnia, v.30, n.5, p.1424-1431, 2001.

FERREIRA, A.C.H.; NEIVA, J.N.M.; RODRIGUEZ, N.M. et al. Valor nutritivo das silagens de capim-elefante com diferentes níveis de subprodutos da indústria do suco de caju. Revista Brasileira de Zootecnia, v.33, n.6, p.1380-1385, 2004.

McDONALD, P. The biochemistry of silage. New York: John Wiley \& Sons, 1981. 207p.

REZENDE, A.V.; EVANGELISTA, A.R.; BARCELOS, A.F. et al. Efeito da mistura da planta de girassol (Helianthus annuus L.), 
durante a ensilagem do capim-elefante (Pennisetum purpureum Schum.) no valor nutritivo da silagem. Revista Brasileira de Zootecnia, v.31, n.5, p.1938-1943, 2002.

RIBEIRO JR., J.I. Análises estatísticas no SAEG (Sistema para análises estatísticas). Viçosa, MG: Editora UFV, 2001. $301 \mathrm{p}$.

RODRIGUES, P.H.M.; BORGATTI, L.M.O.; GOMES, R.W. et al. Efeito da adição de níveis crescentes de polpa cítrica sobre a qualidade fermentativa e o valor nutritivo da silagem de capim-elefante. Revista Brasileira de Zootecnia, v.34, n.4, p.1138-1145, 2005.

SILVA, D.J.; QUEIROZ, A.C. Análise de alimentos: métodos químicos e biológicos. Viçosa, MG: Imprensa Universitária, 2002, 235p.

SOUZA, A.L.; BERNADINO, F.S.; GARCIA, R. et al. Valor nutritivo de silagem de capim-elefante (Pennisetum purpureum Shum) com diferentes níveis de casca de café. Revista Brasileira de Zootecnia, v.32, n.4, p.828-833, 2003.
STAPLES, C.R.; THATCHER, W.W.; MATTOS, R. Fat supplementation strategies for lactating dairy cow diets. In: SIMPÓSIO INTERNACIONAL EM BOVINOCULTURA DE LEITE: novos conceitos em nutrição, 2001, Lavras. Anais... Lavras: 2001. p.161-179.

Van SOEST, P.J. Nutritional ecology of the ruminants. 2.ed. Ithaca: Cornell University Press, 1994. 476p.

Van SOEST, P.J.; MASON, V.C. The influence of Mallard reaction upon the nutritive value of fibrous feeds. Animal Feed Science and Technology, v.32, n.1/3, p.45-53, 1991.

VILELA, D. Utilização do capim elefante na forma de forragem conservada. In: SIMPÓSIO SOBRE CAPIM-ELEFANTE, 1990, Coronel Pacheco. Anais... Juiz de Fora: Embrapa Gado de Leite, 1990. p.89-131.

ZANINE, A.M.; SANTOS, E.M.; FEREIRA, D.J. et al. Avaliação da silagem de capim-elefante com adição de farelo de trigo. Archivos de Zootecnia, v.55, n.209, p.75-84, 2006. 